\title{
A questão da privacidade no contexto da Ciência da Informação: uma análise das Teses e Dissertações do Programa de Pós-Graduação em Ciência da Informação da UNESP Campus de Marília
}

\author{
Ana Paula Grisoto \\ apaulamori7@gmail.com \\ Ricardo Cesar Gonçalves Sant'Ana \\ ricardosantana@marilia.unesp.br \\ José Eduardo Santarem Segundo \\ santarem@usp.br \\ Universidade Estadual Paulista \\ Programa de Pós-Graduação em Ciência da Informação, Marília, Marília, SP, Brasil
}

Resumo: Com a intensificação do uso das Tecnologias de Informação e Comunicação, surge a preocupação com a privacidade, devido ao uso excessivo ou indevido de informações e dados dos indivíduos, refletindo a necessidade de estudos e discussões sobre o tema. Desse modo, essa pesquisa tem como escopo identificar a ocorrência do tema privacidade no corpus de teses e dissertações do Programa de Pós-Graduação em Ciência da Informação (PPGCI) da UNESP/Marília, objetivando evidenciar a incipiência do tema na $\mathrm{Cl}$ e mostrar um panorama das produções que discutem o tema. Para tanto, foi realizado o levantamento bibliográfico sobre privacidade e a Ciência da Informação e delimitou-se que o campo empírico para a coleta de informações seria a produção científica do PPGCl da UNESP/Marília, indexadas no Repositório Institucional UNESP. Os critérios estabelecidos para a busca do termo privacidade foram o título, resumo, palavra-chave e o texto. Verificou-se inicialmente a escassez de publicações na $\mathrm{Cl}$ na elaboração do referencial teórico e o estudo realizado corroborou para evidenciar que há um caminho bastante longo a ser percorrido no que toca discussões e estudos sobre privacidade, principalmente com relação à Ciência da Informação, devido ao baixo número de trabalhos que discutem com profundidade a questão da privacidade no PPGCI da UNESP/Marília.

Palavras-chave: Dados privados; Direito a privacidade; Segurança da informação; Tecnologias de Informação e Comunicação.

The question of privacy in the context of information science: an analysis of theses and dissertations of the Postgraduate Program in Information Science of UNESP Campus Marilia

Abstract: With the increased use of information and communication technologies, there is the concern about privacy, due to excessive or improper use of information and data of individuals, reflecting the need for studies and discussions on the topic. Thus, this research has the objective to identify the occurrence of the subject privacy in the corpus of theses and dissertations of the Graduate Program in Information Science (PPGCI) of UNESP/Marilia, aiming to highlight the theme of incipient in IC and display an overview of productions that discuss the topic. Therefore, it performed the literature on privacy and Information Science and delimited that the empirical field for the collection of information would be the scientific production of PPGCI UNESP/Marilia, Indexed Institutional Repository UNESP. The criteria for the search term privacy were the title, abstract, keywords and text. It was found initially scarcity of publications in the $\mathrm{Cl}$ in developing the theoretical framework and the study corroborated to show that there is a fairly long way to go as regards discussions and studies on privacy, especially in 
relation to the Information Science, due to low number of papers that discuss in depth the issue of privacy in PPGCI UNESP/Marilia.

Keywords: Information and Communication Technologies; Information security; Private data; Right to privacy.

La cuestión de la privacidad en el contexto de la Ciencia de la Información: un análisis de las Tesis y Disertaciones del Programa de Post Graduación en Ciencia de la Información de la UNESP Campus de Marília

Resumo: Con la intensificación del uso de las Tecnologías de Información y Comunicación, surge la preocupación sobre la privacidad, debido al uso excesivo o indebido de información y datos de los individuos, reflejando la necesidad de estudios y discusiones sobre el tema. De ese modo, esta investigación tiene como propósito identificar las ocurrencias sobre el tema de privacidad en el corpus de tesis y disertaciones del Programa de Post Graduación en Ciencia de la Información (PPGCI) de la UNESP/Marília, con el objetivo de evidenciar la insipiencia del tema en la $\mathrm{Cl}$ y mostrar un panorama de los trabajos que discuten el tema. En ese sentido se realizó el levantamiento bibliográfico sobre privacidad y la Ciencia de la Información y se delimitó que el campo empírico para la colecta de información sería la producción científica del PPGCI de la UNESP/Marília, indexada en el Repositorio Institucional UNESP. Los criterios establecidos para la búsqueda del término privacidad fueron: título, resumen, palabra clave y el propio texto. Se verificó inicialmente la escasez de publicaciones en la $\mathrm{Cl}$ durante la elaboración del referencial teórico y el estudio realizado hizo evidente que hay un camino bastante largo a ser recorrido en discusiones y estudios sobre privacidad, principalmente con relación a la Ciencia de la Información, debido al bajo número de trabajos que discuten con profundidad la cuestión de la privacidad en el PPGCI de la UNESP/Marília.

Palabras clave: Datos privados; Derecho a la intimidad; Seguridad de información; Tecnologías de la Información y la Comunicación.

\section{Introdução}

Com o desenvolvimento e a intensificação do uso das redes de computadores e da Internet, novas formas de comunicação e registro de informações foram viabilizados, possibilitando que o acesso e a recuperação de informações ocorram de maneira facilitada.

Neste contexto, em um mundo globalizado, onde cada vez mais se faz o uso de computadores e aparatos tecnológicos para estender a capacidade humana de se comunicar, surge à preocupação com a privacidade devido ao uso indevido ou excessivo de informações e dados dos indivíduos, sejam elas de exposição da vida pessoal na rede mundial de computadores ou do uso de instrumentos de segurança.

Desse modo, surge o culto ao fim da privacidade e da preservação de informações, devido ao fluxo informacional produzido em grande escala e sendo disponibilizados na rede mundial de computadores, ou na chamada "aldeia global" segundo Lévy (1998).

A Ciência da Informação $(\mathrm{Cl})$ que estuda as práticas desde a criação, gestão e disseminação, até a recuperação e uso de informações, está estritamente relacionada com os novos paradigmas que surgem com o aumento do fluxo informacional, este possibilitado principalmente pela criação e difusão das redes de computadores e Internet. O problema de 
privacidade surge como novo desafio, principalmente nos ambientes informacionais digitais, onde as informações e os dados são gerados a partir do uso de aparatos tecnológicos em uma escala exponencial, sendo essencialmente importante que a $\mathrm{Cl}$ discuta questões sobre o tema.

Assim, à medida que surgem esses novos paradigmas, outros questionamentos surgem em conjunto com a necessidade de se desenvolver estudos não somente no que toca a preocupação como o armazenamento, preservação, disseminação e uso de informações em meio digital ou analógico, mas também com a privacidade dos indivíduos referente o uso de informações pessoais e o acesso a seus dados.

A dificuldade de conceitualização do termo privacidade vem desencadeando estudos a fim de encontrar um consenso conceitual para contribuir com estudos futuros sobre o tema, assim tomamos como base deste trabalho o texto Privacy as a Fuzzy Concept: A New Conceptualization of Privacy for Practitioners, dos autores Vasalou, Joinson, Houghton (2014). Eles trabalham com a ideia de construção de um núcleo comum para a definição de privacidade, uma vez que a mesma é bastante complexa e de difícil definição, pois envolve questões sociais, culturais e políticas.

Diante do exposto, o problema desse trabalho parte do pressuposto de que o tema privacidade é de difícil definição e carece de discussões, partindo disso indaga-se se o tema privacidade vem sendo discutido como objeto de estudo no campo da $\mathrm{Cl}$ e, se sim, verificar como ele é abordado.

Assim sendo, essa pesquisa tem como escopo identificar a ocorrência do tema privacidade no corpus de teses e dissertações defendidas no período de 2001 a 2014, no Pós Graduação em Ciência da Informação (PPGCI) da Unesp/Marília nas linhas de pesquisa Informação e Tecnologia, Produção e Organização da Informação e Gestão, Mediação e Uso da Informação, objetivando evidenciar a incipiência do tema na $\mathrm{Cl}$ e mostrar um panorama das produções que discutem o tema, uma vez que o mesmo encontra-se em destaque dentro e fora da academia e nos meios de comunicação.

Para tanto, delimitou-se que o campo empírico para a coleta de informações seria a produção científica de teses e dissertações do PPGCI da UNESP, Campus de Marília, indexadas no Repositório Institucional UNESP ${ }^{1}$, pelo motivo de ser um programa de excelência com conceito CAPES 6, e ainda pelo programa ter três linhas de pesquisa que podem abranger a temática abordada para realização dessa pesquisa. (PROGRAMA..., 2014).

Como procedimento metodológico primeiramente foi realizado o levantamento e documentação bibliográfica sobre o tema central deste trabalho que é privacidade e Ciência da

\footnotetext{
${ }^{1}$ http://repositorio.unesp.br
} 
Informação em periódicos, teses e dissertações da área jurídica e da própria Ciência da Informação, com o escopo de obter o embasamento necessário para o referencial teórico, posteriormente foi realizado a busca no Repositório Institucional UNESP por teses e dissertações do PPGCl , do período de 2001 a 2014, cujo total de dissertações foi 133 e de teses 65. A última etapa foi a elaboração das considerações com base nos resultados obtidos.

Cabe ressaltar que a centralidade deste trabalho consiste em verificar a discussão sobre privacidade no contexto da Ciência da informação, não fazendo parte do escopo a definição do conceito.

\section{Privacidade: origem e evolução}

A palavra privacidade do latim (privates) significa separado do resto significando, portanto, que uma pessoa possa ficar afastada ou isolada em relação aos demais. A primeira e importante menção ao estudo sobre privacidade é conhecida pelo trabalho de Warren e Brandeis, de 1890. Neste trabalho os autores buscam encontrar uma solução para o problema que a evolução tecnológica começa a acarretar, buscam na Common Law, alternativas para que a lei possa atender as necessidades oriundas das modificações sociais, e até mesmo que ela possa ser atualizada atendendo modificações ocorridas. (MENDES, 2008; VASALOU, JOINSON, HOUGHTON, 2014).

A privacidade começa a ser considerada com mais importância e ter maior notoriedade por diversos fatores sociais ocorridos principalmente no século $\mathrm{XX}$, com os novos aparatos tecnológicos de comunicação sendo desenvolvidos, facilitando a disseminação de informações e fotografias de cunho pessoal, ou seja, da esfera privada do indivíduo. Primeiramente desenvolvida para assegurar a proteção familiar (domicílio) e segredo da correspondência, a privacidade começava a ser discutida à medida que a utilização de tecnologias crescia substancialmente e invadiam a esfera da vida privada e doméstica dos indivíduos. (MENDES, 2008).

Anteriormente, o direito a privacidade era visto como sendo parte da burguesia, que objetivava a proteção de celebridades, porém, tem o seu sentido e abrangência modificados, passando a atender todas as esferas sociais, e isso tudo se deu em grande parte pela evolução do Estado no século XX e também a pela evolução tecnológica. (DONEDA, 2010).

\footnotetext{
${ }^{2}$ Foram pesquisadas todas as teses e dissertações do Programa de Pós Graduação em Ciência da Informação da UNESP Campus de Marília indexadas no Repositório Institucional UNESP, até a data 02/02/2014, não coube neste trabalho verificar se todas as teses e dissertações desde o inicio do programa foram indexadas.
} 
Desse modo,

Ao invés de um direito puramente individual, a privacidade assumiu também caráter coletivo - visto que o uso abusivo de dados pessoais pode se referir a grandes grupos de pessoas e não somente a indivíduos determinados. (DONEDA, 2010, p.188).

Neste contexto, o direito a privacidade começa a ser ampliado para além de personalidades e celebridades, atendo também aos interesses do coletivo.

Alguns acontecimentos foram muitos importantes para a abrangência e reconhecimento internacional ao direito à privacidade. Alguns anos após a Segunda Guerra Mundial foi publicada a Declaração Universal dos Direitos Humanos (1948), ela previa em seu artigo XII que "Ninguém será sujeito à interferência em sua vida privada, em sua família, em seu lar ou em sua correspondência, nem a ataque à sua honra e reputação. Todo ser humano tem direito à proteção da lei contra tais interferências ou ataques". (ONU, 1948). Outros documentos com a premissa de garantir o direito a privacidade foram originados a partir dessa declaração: A Convenção Européia para a Proteção dos Direitos do Homem e das Liberdades Fundamentais; Pacto Internacional de Direitos Civis e Políticos; Convenção Americana sobre Direitos Humanos; Pacto de São José da Costa Rica. (MENDES, 2008).

A Constituição brasileira de 1988 diz em seu art. 5, inciso X que "são invioláveis a intimidade, a vida privada, a honra e a imagem das pessoas, assegurado o direito a indenização pelo dano material ou moral decorrente de sua violação".

Portanto, a privacidade sofre alterações à medida que as transformações sociais, políticas, culturais e econômicas vão ocorrendo, partindo do pressuposto que o núcleo duro de seu conceito é inviolável, pois tenta garantir ao indivíduo o direito sobre a sua vida privada e sobre a disponibilização de seus dados e a utilização de suas informações por terceiros.

O direito à privacidade é um direito humano de primeira dimensão que se configura no direito do indivíduo de estar só, considerando-se a possibilidade que deve ter toda pessoa de excluir do conhecimento de terceiros aquilo que a ela só se refere, e que diz respeito ao seu modo de ser no âmbito da vida privada. O direito à privacidade é universal, inalienável e indivisível e está intimamente ligado à dignidade humana. (GALVÃO; RICARTE, 2012, p.98)

À medida que as transformações vão ocorrendo e modificando a sociedade, se torna cada vez mais substancial a criação de legislações capazes de garantir os direitos aos cidadãos ao acesso a informações, bem como na proteção de informações de cunho pessoal.

A Lei n.o 12.527/11 de Acesso à Informação criada para assegurar o acesso á informação a todos cidadãos, gera discussões sobre a disponibilização e proteção de informações, pois nem todas as informações são passiveis de serem disponibilizadas, segundo prescreve o seu art. 23: 
Art. 23. São consideradas imprescindíveis à segurança da sociedade ou do Estado e, portanto, passíveis de classificação as informações cuja divulgação ou acesso irrestrito possam:

I - pôr em risco a defesa e a soberania nacionais ou a integridade do território nacional;

II - prejudicar ou pôr em risco a condução de negociações ou as relações internacionais do País, ou as que tenham sido fornecidas em caráter sigiloso por outros Estados e organismos internacionais;

III - pôr em risco a vida, a segurança ou a saúde da população;

IV - oferecer elevado risco à estabilidade financeira, econômica ou monetária do País;

$\mathrm{V}$ - prejudicar ou causar risco a planos ou operações estratégicos das Forças Armadas;

$\mathrm{VI}$ - prejudicar ou causar risco a projetos de pesquisa e desenvolvimento científico ou tecnológico, assim como a sistemas, bens, instalações ou áreas de interesse estratégico nacional;

VII - pôr em risco a segurança de instituições ou de altas autoridades nacionais ou estrangeiras e seus familiares; ou

VIII - comprometer atividades de inteligência, bem como de investigação ou de fiscalização em andamento, relacionadas com a prevenção com a prevenção ou repressão de infrações. (BRASIL, 2011).

Com base nesse artigo é possível verificar que os usos de algumas informações devem ser mantidos e utilizados com restrições, para garantir a proteção e privacidade dos indivíduos, e para que nenhum dano seja causado a terceiros.

A criação do Marco Civil da Internet dispõe

sobre princípios, garantias, direitos e deveres para o uso da internet no Brasil e determina as diretrizes para atuação da União, dos Estados, do Distrito Federal e dos Municípios, busca garantir dentre outras coisas, a segurança no acesso e na disponibilização dos dados. (BRASIL, 2014).

Observa-se com a Lei de Acesso a Informação e o Marco Civil, que algumas medidas estão sendo tomadas para garantir a integridade e dignidade humana no que toca a proteção de suas informações e também do direito ao acesso a informações púbicas.

Porém, o conceito de privacidade é bastante complexo e de difícil definição, pois envolve questões subjetivas, ou seja, de valor relacionado ao indivíduo e a dignidade humana e assim requer reflexões de todas as áreas do conhecimento, porém, muito do que vem sendo discutido e estudado acerca de privacidade, majoritariamente advêm da área jurídica. (VASALOU; JOINSON; HOUGHTON, 2014).

Com a intensificação do uso das redes de computadores e tecnologias, surgem embates mais abrangentes relacionados à privacidade, onde o indivíduo vive em constante processo decisório de quais informações deve ou não disponibilizar, e se os dados disponibilizados podem ou não gerar prejuízos futuros, a título de exemplificação cita-se que isso pode ocorrer dentre outros usos da tecnologia, pelas redes sociais, pois segundo Westin (1970, p. 7) 
O desejo do indivíduo por privacidade nunca é absoluto, uma vez que a participação em sociedade é igualmente importante. Assim, cada indivíduo está continuamente envolvido em um processo pessoal de equilíbrio entre o desejo de privacidade e o desejo de exposição e comunicação com os outros, à luz de condições do ambiente e de normas sociais na sociedade em que vive. $\mathrm{O}$ indivíduo o faz em face das pressões da curiosidade dos outros e dos processos de vigilância que toda sociedade necessita para a implementação de normas sociais.

O uso das redes de computadores e a combinação de diversos instrumentos tecnológicos possibilitam a coleta, o registro, o processamento, o cruzamento, a organização e a transmissão de dados, nunca antes imaginável, tornando tangível a possibilidade de obtenção de informações de cunho valioso sobre os cidadãos, sendo estas, um auxílio na tomada de decisões, sejam elas políticas, sociais ou econômicas, agravando o problema de privacidade individual e coletiva. (MENDES, 2008).

Esse tipo de informação pode ser considerado como sensível e foi categorizada dessa forma segundo Mendes (2008, p. 62)

a partir da percepção de que o armazenamento, processamento e circulação de alguns tipos de dados podem se constituir em uma ameaça maior à personalidade individual, especialmente, se utilizados para condutas discriminatórias. Os dados referentes à raça, opção sexual, saúde e religião, são exemplos desse tipo.

Para Doneda (2010, p. 189)

A categoria dos dados sensíveis - que são, em suma, dados que revelam informações sobre uma pessoa que podem potencialmente dar origem à discriminação caso sejam conhecidos por terceiros - além de levar aos seus limites o nível de proteção concedido aos dados pessoais, constitui um ponto de análise valioso por possibilitar identificar a sensibilidade de um ordenamento aos problemas mais graves que envolvem a informação pessoal e as garantias fundamentais da pessoa, como a sua própria liberdade.

Esses dados são considerados sensíveis, portanto, pelo grau elevado de problemas que podem gerar à privacidade individual e coletiva, quando de sua má utilização por terceiros, merecendo uma proteção, discussão e estudos mais intensos, uma vez que a informação passa a ser cada vez mais valorizada, e considerada como insumo valioso na contemporaneidade.

\section{A Sociedade da Informação e a Privacidade}

O homem desenvolve tecnologias que possibilitam o aumento de sua capaciadade nativa de se comunicar, resolver problemas, tomar decisões e de ter uma melhor condição de vida, e ainda desenvolve mecanismos capazes de armazenar essas informações de modo otimizado. (DEBONS, 2008; OLIVEIRA, RODRIGUES, 2011). 
Segundo Marcondes (2001, p. 61) "na atualidade, constata-se que a informação se tornou um recurso cada vez mais valorizado como viabilizador de decisões e de processos de conhecimento/inteligência nos mais diferentes campos", ou seja, a informação caracteriza-se como insumo fundamental na tomada de decisões,

nos processos culturais, nos processos de ensino e aprendizagem, nos processos de aquisição e construção de conhecimento para pesquisa científica e tecnológica e em diversos outros setores ou atividades nos quais o conhecimento humano se faz necessário. (ALVES, 2010, p. 11).

Para Santos (2009, p. 13) a informação "é parte integrante de nosso dia-a-dia, cada vez mais necessária ao desenvolvimento de competências e à execução de quase todas as atividades humanas".

Segundo Ilharco (2003, p. 29)

[...] as sociedades comtemporâneas mais avançadas baseiam as suas actividades, a comunicação entre as pessoas a as instituições em informação gerada e gerida por tecnologias, as quais, sugestivamente, receberam o nome de tecnologias de informação. Este desenvolvimento tem provocado alterações importantes em termos políticos, sociais e económicos e ambientais.

As Tecnologias de Informação e Comunicação (TIC) contribuem para disseminação da informação e para a criação de ambientes férteis para a construção do conhecimento, estes espaços possibilitam o fácil acesso as informações e provê o acesso a um número cada vez maior de dados e informações. O conhecimento por sua vez, possui papel fundamental no desenvolvimento social, cultural e econômico.

Desse modo, Doneda (2010, p. 184) considera que

O homem recebe informações, delimita seu universo a partir das informações que recebe. Suas ações podem ser determinadas pelas informações que obtém, bem como pelo uso que delas faz. Por outro lado, o homem também é produtor de informações. Informações estas que podem igualmente influenciar outros homens, modelando a impressão e a concepção que outras pessoas tenham sobre cada um de nós.

Assim, o desenvolvimento da tecnologia e dos aparatos tecnológicos sempre estiveram estreitamente ligados com a informação e o conhecimento, que a partir destes foi possível uma verdadeira revolução, passando da era agrícola para industrial e posteriormente para a pós-industrial, ou então chamada Sociedade da Informação. (MATTELART, 2006).

A Sociedade da Informação comumente conhecida atualmente teve maior notoriedade após a Segunda Guerra Mundial, onde a utilização de informações alinhada ao desenvolvimento de tecnologias de comunicação foram extremamente importantes para as estratégias de guerra. 
Porém, Mattelart (2006) ressalta que a informação discutida como geradora de inteligência foi abordada por Bacon em 1627, em sua obra New Atlantis e a sociedade da informação como é conhecida atualmente, foi pensada de diversas formas dentro das diversas áreas do saber e por muitas pessoas como políticos, cientistas, industriais, militares que já possuíam a noção de informação como alicerce para a construção de conhecimento, assim como para o desenvolvimento da sociedade, ou seja a Sociedade da Informação não é uma discussão recente que surgiu com maior notoriedade após a Segunda Guerra mundial, a concepção que temos hoje de Sociedade da Informação que é nova, alinhada ao uso massivo das TIC.

Segundo Takahashi (2000, p. 5, grifo do autor)

A sociedade da informação não é um modismo. Representa uma profunda mudança na organização da sociedade e da economia, havendo quem a considere um novo paradigma técnico-econômico. É um fenômeno global, com elevado potencial transformador das atividades sociais e econômicas, uma vez que a estrutura e a dinâmica dessas atividades inevitavelmente serão, em alguma medida, afetadas pela infra-estrutura de informações disponível. É também acentuada sua dimensão político-econômica, decorrente da contribuição da infra-estrutura de informações para que as regiões sejam mais ou menos atraentes em relação aos negócios e empreendimentos. Sua importância assemelha-se à de uma boa estrada de rodagem para o sucesso econômico das localidades.

Desse modo, a Sociedade da Informação conduz a verdadeiras transformações no cenário econômico, político e social, alinhada a difusão acelerada das TIC promovem transformações nas cadeias produtivas, onde o uso massivo de tecnologia proporciona a melhoria e eficiência nos processos de produção no que toca o uso de capital, matérias primas e capital humano.

Assim, as tecnologias são na Sociedade da Informação o meio que conduzem as transformações, e por meio dos aparatos tecnológicos e o acesso a Internet, modificam a maneira de se pensar a informação. A computação conduz mudanças de paradigmas, onde a comunicação, ou seja, a transmissão e recepção de dados e os conteúdos (imagens, musica, livros, etc.) passam a ter uma gama de possibilidades e aplicações para os indivíduos. (TAKAHASHI, 2000).

Desse modo, considera Perez Luño (1996, p. 43)

na sociedade atual, a informação converte-se em poder a partir do momento em que a informática permite transformar informações parciais e dispersas em informações em massa e organizadas, o que torna imperativa a regulamentação jurídica dessas técnicas para a proteção da privacidade dos cidadãos.

O uso das TIC e a combinação de diversos instrumentos tecnológicos permite a coleta, registro, processamento, cruzamento, organização e a transmissão de dados, nunca 
antes possível, originando a possibilidade de obtenção de informações sobre os indivíduos, cujo valor é agregado a possibilidade de se tomar decisões econômicas, políticas e sociais. (MENDES, 2008).

E Mendes (2008, p. 17-18) discorre que a

A evolução do direito à privacidade prosseguiu para se adaptar às novas transformações sociais ocasionadas pela revolução da tecnologia da informação que possibilitou a coleta e o processamento dos dados pessoais dos cidadãos de forma pioneira. Além de adquirir um caráter positivo e de ser reconhecido no âmbito internacional, o direito à privacidade transformou-se para ensejar o nascimento da disciplina de proteção de dados pessoais, à medida que surgiram novos desafios ao ordenamento jurídico a partir do tratamento informatizado dos dados.

Porém, a informática não deve ser vista como o instrumento causador do problema de privacidade, o seu desenvolvimento deve-se se dar de maneira harmonizada com a preservação da privacidade. (GARFINKEL, 2000).

A Sociedade da Informação é, portanto, caracterizada pela complexidade, dinamismo e competitividade crescente e assim, molda uma nova forma de organização e utilização do saber, pautada na informação como fonte de desenvolvimento dos diversos setores da sociedade, tendo como objetivo estabelecer novas fontes de riqueza por meio da detenção de informações no desenvolvimento de conhecimento para a realização de pesquisas e tecnologia.

Dessa forma, causa bastante impacto nos diversos segmentos da sociedade, uma vez que modifica a forma de se pensar e olhar a informação, e isso pode ocasionar dentre outras coisas, o problema da privacidade, devido ao uso massivo e indevido de informações e dados para alcançar tais objetivos.

\section{Resultados}

A busca realizada no Repositório Institucional da UNESP por teses e dissertações Programa de Pós Graduação em Ciência da Informação da Unesp Campus de Marília, recuperou um total de 133 dissertações, cuja primeira data verificada é 2001 e a última é 2014 e 65 teses, a primeira data verificada é de 2007 e a última 2014.

A busca pelo termo privacidade se deteve na verificação de discussões do tema no contexto da Ciência da Informação e como a mesma se posiciona sobre esse assunto e em discussões concernentes à privacidade no uso de tecnologias, acesso a dados (pessoais ou não). 
Os critérios utilizados para a realização da busca foram encontrar a palavra privacidade no título, resumo, palavras-chave e no texto, para posterior verificação do contexto em que a palavra privacidade encontrada é discutida.

\subsection{Resultado encontrado nas dissertações}

Das 133 dissertações recuperadas 104 não apresentaram o termo privacidade em nenhum dos critérios estabelecidos para a busca, apenas 29 possuem o termo privacidade em apenas um dos critérios, o texto. Das 29 dissertações, 25 delas foram consideradas como sendo de pouca relevância para o propósito do trabalho, pois a menção ao termo privacidade se deteve aos seguintes contextos: Privacidade no acesso a dados dentro de instituições; Privacidade de usuários no acesso a um sistema de informação; Privacidade médico/paciente e suas informações; Privacidade dos participantes da pesquisa; Direito a privacidade no acesso a documentação arquivística; Privacidade dos procedimentos/ realização da pesquisa. Embora os assuntos listados sejam importantes e passiveis de discussão, nenhum desses 25 trabalhos se aprofundou na questão privacidade como objeto de discussão. Com relação a data de publicação, não houve nenhum ano com relevância de publicações acerca do termo.

Apenas quatro dissertações apresentaram o termo privacidade de forma considerada relevante ao propósito deste trabalho, embora tenha sido em apenas no critério texto, elas trouxeram uma discussão mais aprofundada sobre o tema, sendo eles:

1) Discussão da privacidade com o uso da Internet e questões autorais de 2002;

2) Privacidade na ética profissional de 2006;

3) Privacidade sobre os direitos de acesso a informação de 2006;

4) privacidade da divulgação de informações de prontuários de pacientes de 2014.

Para visualização dos resultados segue o gráfico da recuperação do termo privacidade em dissertações. 
Gráfico 1 - Recuperação do termo privacidade em dissertações

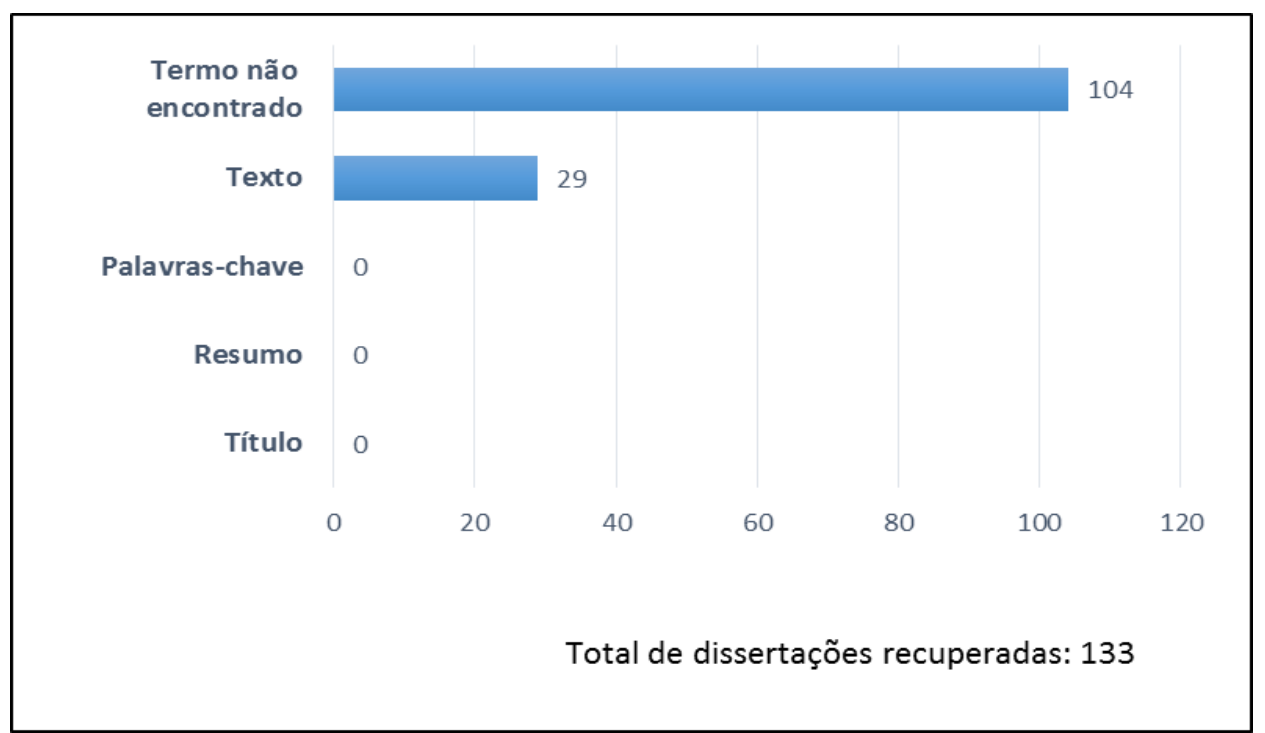

Fonte: elaborado pelos autores com base nas dissertações recuperadas do Repositório Institucional UNESP

\subsection{Resultado encontrado nas teses}

$\mathrm{Na}$ verificação das teses, o total recuperado foi de 65 trabalhos, 46 deles não apresentam o termo privacidade em nenhum dos critérios estabelecidos, apenas 19 apresentam o termo em um dos critérios, o texto, e 17 delas foram consideradas de pouca relevância para o escopo deste trabalho, pois trazem as mesmas questões já listadas na recuperação das dissertações enquadradas como sendo pouco relevantes. Apenas duas teses foram consideradas relevantes ao propósito deste trabalho e possuem o termo privacidade em seu texto. As discussões são:

1) Privacidade no acesso à informação de e-mail e no uso da Internet de 2008;

2) Privacidade de usuários em ambientes informacionais digitais de 2010.

Para melhor visualizar os resultados da recuperação do termo privacidade em teses, segue o gráfico 2 . 
Gráfico 2 - Recuperação do termo privacidade em teses

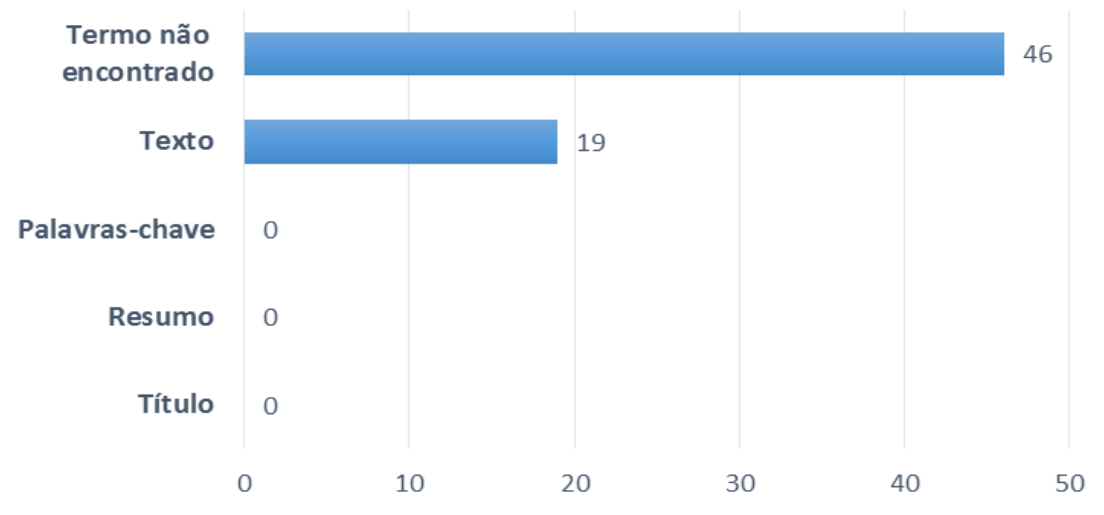

Total de teses recuperadas: 65

Fonte: elaborado pelos autores com base nas teses recuperadas do Repositório Institucional UNESP

Para melhor visualização dos resultados, segue o Quadro 1 com informações referentes aos trabalhos que discutem privacidade no PPGCI UNESP de Marília.

Quadro 1 - Trabalhos com discussões sobre privacidade

\begin{tabular}{|c|c|c|c|c|}
\hline & Título & $\begin{array}{l}\text { Linha de } \\
\text { Pesquisa }\end{array}$ & $\begin{array}{c}\text { Quantidade de } \\
\text { referências bibliográficas } \\
\text { utilizadas sobre } \\
\text { privacidade }\end{array}$ & Ano de publicação \\
\hline \multirow{4}{*}{ Dissertações } & $\begin{array}{l}\text { A proteção dos direitos } \\
\text { autorais a partir da realidade } \\
\text { Internet: a perspectiva } \\
\text { brasileira }\end{array}$ & $\begin{array}{l}\text { Produção e } \\
\text { Organização da } \\
\text { Informação }\end{array}$ & 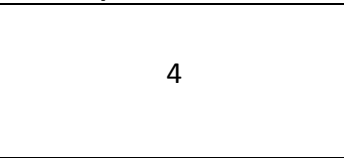 & 2002 \\
\hline & $\begin{array}{l}\text { O conceito assunto na } \\
\text { arquivística: uma reflexão } \\
\text { em arquivos permanentes a } \\
\text { partir do evento - I soggetti e } \\
\text { altri apparati di } \\
\text { indicizzazione in archivistica: } \\
\text { ipotesi di lavoro }\end{array}$ & $\begin{array}{l}\text { Produção e } \\
\text { Organização da } \\
\text { Informação }\end{array}$ & 1 & 2006 \\
\hline & $\begin{array}{l}\text { Aspectos éticos em } \\
\text { representação do } \\
\text { conhecimento em temáticas } \\
\text { relativas à homossexualidade } \\
\text { masculina: uma análise da } \\
\text { precisão em linguagens de } \\
\text { indexação brasileiras }\end{array}$ & $\begin{array}{l}\text { Produção e } \\
\text { Organização da } \\
\text { Informação }\end{array}$ & 1 & 2006 \\
\hline & $\begin{array}{l}\text { O prontuário do paciente na } \\
\text { perspectiva arquivística }\end{array}$ & $\begin{array}{l}\text { Produção e } \\
\text { Organização da } \\
\text { Informação } \\
\end{array}$ & 1 & 2014 \\
\hline \multirow[t]{2}{*}{ Teses } & $\begin{array}{l}\text { O assunto do e-mail como } \\
\text { indício de fraude: } \\
\text { contribuições da organização } \\
\text { da informação para a } \\
\text { prevenção criminal }\end{array}$ & $\begin{array}{l}\text { Produção e } \\
\text { Organização da } \\
\text { Informação }\end{array}$ & 3 & 2008 \\
\hline & $\begin{array}{l}\text { Arquitetura da informação } \\
\text { para biblioteca digital } \\
\text { personalizável }\end{array}$ & $\begin{array}{l}\text { Informação e } \\
\text { Tecnologia }\end{array}$ & 1 & 2010 \\
\hline
\end{tabular}

Fonte: Elaborado pelos autores 
Dos trabalhos cujo texto contemplava a discussão sobre privacidade, a linha de pesquisa que teve maior incidência foi a de Produção e Organização da Informação, com 4 dissertações e 1 tese. A linha de pesquisa Informação e Tecnologia possui 1 tese.

A análise das referências bibliográficas dos trabalhos sobre privacidade se deteve apenas na verificação de seus títulos e da verificação das citações utilizadas nas dissertações e teses, não cabendo nesse trabalho uma análise mais aprofundada de cada uma das referências bibliográficas. As referências bibliográficas trazem pouco material específico de privacidade, em suma os documentos referentes à privacidade estão contidos em trabalhos sobre direito autoral; segurança na Internet e criptografia; ética e sigilo médio paciente.

\section{Conclusões}

A Ciência da Informação como área do saber pauta-se no desenvolvimento de pesquisas e estudos realacionados a informação, desde a sua criação, gestão, preservação, recupração, acesso e uso, e assim evoluiu em conjunto com as pesquisas de desenvolvimento de tecnologias.

Desse modo, a criação de aparatos tecnológicos, das redes de computadores e da Internet possibilitaram que novos ambientes informacionas fossem criados, gerando novos desafios no que concerne o tratamento, a preservação e privacidade de informações e dados, devido as produções em larga escala vividas na atualidade.

Segundo a literatura o termo privacidade é de difícil conceitualização, pois envolve questões culturais, sociais, políticas, e questões da dignidade humana, intrínsecas a cada individuo, ou seja, cada indivíduo enxerga a privacidade de sua maneira, de acordo com seus preceitos e vivencias, porém de acordo com o estudo elaborado pelos autores Vasalou, Joinson e Houghton (2014) eles apontam que a privacidade tem um núcleo comum e que este pode ser utilizado para representar e contribuir com estudos sobre o tema. Embora não seja totalmente comum para todos os indivíduos, o termo em suma designa aquilo que lhe é próprio, particular, que diz respeito somente a si.

Assim sendo, em uma sociedade onde se faz uso cada vez maior das TIC, seja para o uso de tarefas diárias cotidiano, do trabalho ou lazer, o indivíduo acaba abrindo mão de sua liberdade, privacidade em troca muitas de falsa segurança e de reconhecimento pessoal e social, a título de exemplo têm-se as transações bancárias, as redes sociais, dentre outros, refletindo diretamente na vida de cada individuo quando do uso indevido de seus dados e informações. $\mathrm{O}$ uso massivo de informações e dados dos indivíduos fere o direito a privacidade individual e coletiva, quando obtida de forma indevida e não consensual gerando conflitos muito abrangentes. 
De acordo com a pesquisa realizada nas teses e dissertações Programa de PósGraduação em Ciência da Informação da Unesp Campus de Marília, podemos observar o baixo número de trabalhos que abordam a questão da privacidade, somente as linhas de pesquisa Informação e Tecnologia e Produção e Organização da Informação, possuem alguns trabalhos abordando o tema. Com isso vemos que há um caminho bastante longo a ser percorrido no que toca discussões a cerca da privacidade e acesso a dados, principalmente com relação à Ciência da Informação, que deveria participar mais ativamente de discussões, elaboração de projetos concernentes a esse assunto, uma vez que esse tema gera bastante dúvidas e conflitos.

A escassez de publicações na $\mathrm{Cl}$ foi percebida também na elaboração do arcabouço teórico que subsidiaram a realização desse trabalho, pois grande parte das publicações provém da área do Direito, refletindo mais uma vez a necessidade de um posicionamento mais ativo da $\mathrm{Cl}$, entende-se que há um caminho muito longo e tortuoso a se trilhar para a mudança de tal cenário, porém a temática é bastante profícua para a construção e elaboração de pesquisas sobre o tema.

A realização de trabalhos futuros, como a investigação mais abrangente em outros programas de Pós-Graduação em Ciência da Informação ou a investigação em periódicos científicos podem gerar um panorama mais abrangente com relação à discussão desse tema, trazendo mais contribuições.

Desse modo, entende-se que a $\mathrm{Cl}$ tem papel fundamental na Sociedade da Informação, uma vez, que seus estudos e pesquisas podem gerar contribuições para o problema de gestão informacional e privacidade, delineando o melhor caminho para o acesso e uso das informações, respeitando a privacidade individual e coletiva.

\section{Referencias}

ALVES, R. C. V. Metadados como elementos do processo de catalogação. 2010. 132 f. Tese (Doutorado em Ciência da Informação)-Faculdade de Filosofia Ciências, Universidade Estadual Paulista, Marília, 2010.

BRASIL. Constituição da República Federativa do Brasil de 1988. Disponível em:<http://www.planalto.gov.br/ccivil 03/constituicao/constituicao.htm>. Acesso em: 03 fev. 2014

BRASIL. Marco Civil da Internet. Lei 12.965, de 23 de abril de 2014. Estabelece princípios, garantias, direitos e deveres para o uso da Internet no Brasil. Disponível em: $<$ http://www.planalto.gov.br/ccivil 03/ ato2011-2014/2014/lei/l12965.htm>. Acesso em: 08 dez. 2014.

BRASIL. Lei de Acesso à Informação. Lei 12/527, de 18 de novembro de 2011. Regula o acesso

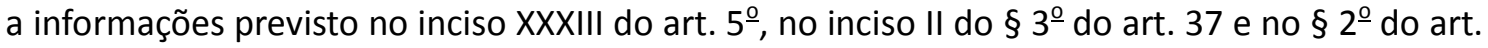


216 da Constituição Federal; altera a Lei no 8.112, de 11 de dezembro de 1990; revoga a Lei $\mathrm{n}^{\circ}$ 11.111, de 5 de maio de 2005, e dispositivos da Lei $n^{\circ}$ 8.159, de 8 de janeiro de 1991; e dá outras providências.Disponível em: < http://www.planalto.gov.br/ccivil 03/ ato20112014/2011/lei/l12527.htm>. Acesso em: 08 dez. 2014.

CAMARGO, L. S. de A. de. Arquitetura da informação para biblioteca digital personalizável. 2004. 143 f. Dissertação (mestrado) - Universidade Estadual Paulista, Faculdade de Filosofia e Ciências, 2004. Disponível em: <http://base.repositorio.unesp.br/handle/11449/93705>. Acesso em: 26 mar. 2015.

CIOCCA, I. G. 0 prontuário do paciente na perspectiva arquivística. 2014. 100 f. Dissertação (mestrado) - Universidade Estadual Paulista, Faculdade de Filosofia e Ciências de Marília, 2014. Disponível em: <http://base.repositorio.unesp.br/handle/11449/113864>. Acesso em: 26 mar. 2015.

DEBONS, A. Information Science 101. United States of America: Scarecrow Press, 2008.

DONEDA, D. Privacidade e transparência no aceso à informação pública. Zaragoza: Prenssas Universitárias de Zaragoza, 2010. Disponível em: <http://www.egov.ufsc.br/portal/sites/default/files/lefis11-09.pdf>. Acesso em: 08 dez. 2014.

FURLANETO NETO, M. 0 assunto do e-mail como indício de fraude: contribuições da organização da informação para a prevenção criminal. 2008. 262 f. Tese (doutorado) Universidade Estadual Paulista, faculdade de Filosofia e Ciências, 2008. Disponível em:

<http://base.repositorio.unesp.br/handle/11449/103390>. Acesso em: 26 mar. 2015.

GALVÃO, M. C. B.; RICARTE, I. L. M. Prontuário do Paciente. 1. ed. Rio de Janeiro: Guanabara Koogan, 2012. v. 1, 344p.

GARFINKEL, S. Database Nation: the death of privacy in the 21th century. O'Reilly Media: California, 2000.

PÉREZ LUÑO, A. E. Manual de Informática e Derecho. Barcelona: Editorial Ariel, 1996.

ILHARCO, F. A Filosofia da informação. Lisboa: Universidade Católica Editora, 2003. 202 p.

LEVY, P. A Inteligência Coletiva: por uma antropologia do ciberespaço. Rio de Janeiro: Loyola, 1998. 214p.

MATTELART, A. História da sociedade da informação. São Paulo: Loyola, 2002, 197p

MARCONDES, C. H. Representação e economia da informação. Ciência da Informação, Brasília, v. 30, n. 1, p. 61-70, jan./abr. 2001. Disponível em: <http://www.scielo.br/pdf/ci/v30n1/a08v30n1.pdf>. Acesso em: 10 jul. 2013.

MENDES, L. S. Transparência e privacidade: violação e proteção da informação pessoal na sociedade de consumo. 2008. 156 f. Dissertação (Mestrado em Direito)-Faculdade de Direito, Universidade de Brasília, DF, 2008. Disponivel em:

$<$ http://repositorio.unb.br/bitstream/10482/4782/1/DISSERTACAO\%20LAURA.pdf >. Acesso em: 05 jan. 2014.

MONÇÃO, J. L. O conceito assunto na arquivística: uma reflexão em arquivos permanentes a partir do evento - I soggetti e altri apparati di indicizzazione in archivistica: ipotesi di lavoro. 2006. 83 f. Dissertação (mestrado) - Universidade Estadual Paulista, Faculdade de Filosofia e Ciências, 2006. Disponível em: <http://base.repositorio.unesp.br/handle/11449/95534>. Acesso em: 26 mar. 2015. 
OLIVEIRA, E. B.; RODRIGUES, G. M. O conceito de memória na Ciência da Informação: análise das teses e dissertações dos programas de pós-graduação no Brasil. Liinc em Revista, Rio de Janeiro, v. 7, n. 1, p. 311-328, mar. 2011. Disponível em:

$<$ http://revista.ibict.br/liinc/index.php/liinc/article/viewFile/416/298>. Acesso em: 10 jul. 2014.

ONU. Declaração Universal dos Direitos Humanos. Resolução no. 217ạ (III) da Assembleia Geral das Nações Unidas, de 10 de dezembro de 1948.

PINHO, F. A. Aspectos éticos em representação do conhecimento em temáticas relativas à homossexualidade masculina: uma análise da precisão em linguagens de indexação brasileiras. 2010. 149 f. Tese (doutorado) - Universidade Estadual Paulista, Faculdade de Filosofia e Ciências, 2010. Disponível em: <http://base.repositorio.unesp.br/handle/11449/103379>. Acesso em: 26 mar. 2015.

PROGRAMA DE PÓS GRADUAÇÃO EM CIÊNCIA DA INFORMAÇÃO. Apresentação. Disponível em: <http://www.marilia.unesp.br/\#!/posci>. Acesso em: 26 mar. 2015.

SANTOS, P. L. V. A. da C. Catalogação: trajetória para um código internacional. Niterói: Intertexto, 2009.

SOLA, J. E. M. A proteção dos direitos autorais a partir da realidade Internet: a perspectiva brasileira. 2002. 172 f. Dissertação (mestrado) - Universidade Estadual Paulista, Faculdade de Filosofia e Ciências, 2002. Disponível em:

<http://base.repositorio.unesp.br/handle/11449/88197>. Acesso em: 26 mar. 2015.

TAKAHASHI, T. (org.). Sociedade da informação no Brasil: livro verde. Brasília: Ministério da Ciência e Tecnologia, 2000.

VASALOU, A.; JOINSON, A.; HOUGHTON, D. Privacy as a Fuzzy Concept: A New Conceptualization of Privacy for Practitioners. Journal of the Association for Information Science and Technology, v. 66, n. 5, May 2014.

WARREN, S. D.; BRANDEIS, L. D. The Right to Privacy. Harvard Law Review, v. 4, December 15, 1890, n. 5. Disponível em:

$<$ http://www.english.illinois.edu/-people-

/faculty/debaron/582/582\%20readings/right\%20to\%20privacy.pdf>. Acesso em: 26 mar. 2015.

WESTIN, A. Privacy and Freedom. Nova York: Atheneum, 1970.

Recebido/Recibido/Received: 2015-06-11.

Aceitado/Aceptado/Accepted: 2015-07-31. 